\title{
Research
}

\section{Citizen, Science, Highways, and Wildlife: Using a Web-based GIS to Engage Citizens in Collecting Wildlife Information}

\author{
$\underline{\text { Tracy Lee }}^{1}, \underline{\text { Michael S. Quinn }}^{l}$, and Danah Duke ${ }^{l}$
}

\begin{abstract}
Road Watch in the Pass is a citizen-science project that engages local citizens in reporting wildlife observations along a 44-km stretch of Highway 3 through Crowsnest Pass in southwestern Alberta, Canada. The numbers of wildlife vehicle collisions and a recent proposal to expand the highway have raised concerns from both human safety and wildlife conservation perspectives. Through the use of a web-based GIS, interested citizens can contribute information that will be instrumental in making final decisions concerning measures to mitigate the effects of highway expansion. Currently, 58 people have contributed over 713 observations to Road Watch. We performed a preliminary comparison of 11 months of Road Watch observations and wildlife mortality data for the same time period to demonstrate that the use of citizen science not only augments more conventional approaches, but also results in the emergence of new knowledge and insights. A Kappa index of agreement of $14 \%$ indicates poor agreement between the data sets, highlighting that wildlife successfully cross the highway in areas not identified by the wildlife mortality data. This has important implications for design and mitigation efforts for Highway 3 and other roadways.
\end{abstract}

Key Words: citizen science; Crowsnest Pass; highways; road ecology; transportation; web-based GIS; wildlife-vehicle collisions

\section{INTRODUCTION}

Roads are the most ubiquitous and spatially extensive human footprint on Earth (Forman et al. 2003). The interface between roads and wildlife has emerged as an international issue of economic, human safety, and conservation significance. Whereas roads function as essential movement corridors for people and products, their physical form constitutes a significant linear disturbance on the landscape. The horizontal flow of organisms and natural processes across roadways results in negative outcomes for both human and natural systems. For example, there were 30,736 reported collisions between motor vehicles and animals in Canada in 2002 (L-P Tardiff and Associates 2003). Non-fatal injuries were sustained by vehicle occupants in 1887 of the collisions, and 23 collisions resulted in human fatalities. The direct annual monetary cost of animal-vehicle collisions in Canada is estimated to be $\$ 200$ million CAD (L-P
Tardif and Associates 2003). Forman and Alexander (1998) indicate that vehicle collisions are now the leading cause of direct anthropogenic mortality for land vertebrates. In addition to direct mortality, roads have detrimental effects on wildlife through barrier effects, habitat fragmentation, and disruption of gene flow and metapopulation dynamics (Andrews 1990, Forman and Alexander 1998, Spellerberg 1998, Trombulak and Frissell 2000, Sherwood et al. 2002, Forman et al. 2003).

The growing recognition of problems associated with the relationship between roads and wildlife has led to calls for design and mitigation solutions to abate negative effects. Thoughtful and creative design of the physical characteristics and alignment of roads should be the first approach to minimizing road-wildlife conflicts (Forman et al. 2003). Mitigation measures to influence human and/or animal behaviour are the next line of action to minimize the social and ecological consequences of 
roads. The effectiveness of both design and mitigation measures is predicated on adequately understanding the behaviour of target wildlife species. In particular, the alignment of roads and the location of mitigative interventions will best lessen road-wildlife conflict when information on natural linkage zones is known, modeled, and taken into design consideration (Beier and Loe 1992, Foster and Humphrey 1995, Clevenger and Waltho 2000, Malo et al. 2004, Seiler 2005). Obtaining such information requires research and monitoring of wildlife movements over adequate periods of time to identify meaningful patterns. There is tremendous potential to include citizen science as one approach to gathering these data.

Citizen science is defined as the participation of non-scientists in data collection for scientific investigations (Trumbull et al. 2000). Citizen science complements and enhances more conventional scientific studies (Eden 1996, Heiman 1997, Au et al. 2000, Pattengill-Semmens and Semmens 2003). The role of citizen science in the realm of ecological monitoring is particularly valuable. Governments often do not have the resources to generate the baseline and on-going monitoring data required to address complex environmental issues because ecological monitoring is expensive, labor intensive, and time consuming (Au et al. 2000, Pattengill-Semmens and Semmens 2003).

Here, we describe a citizen-science project that employs a web-based tool to facilitate the collection, analysis, and communication of information related to wildlife movement across and adjacent to a highway that runs through the Municipality of Crowsnest Pass, Alberta, Canada. The data are being collected to support decision making for mitigation of a planned highway expansion. The project engages local citizens in the issues of wildlife movement and safety, and highlights the value of local knowledge and citizen data collection. The purpose here is to describe the development of the project, including the process of citizen participation, and present preliminary findings that highlight the value of citizen-science data. We also discuss the potential for this project to evolve into a community-based research project that affects social change.

\section{METHODS}

\section{Study area}

The Municipality of Crowsnest Pass is situated in a rare east-west corridor bisecting the Rocky Mountains in southwestern Alberta and southeastern British Columbia. The elevation of the municipality ranges from $1113 \mathrm{~m}$ at the valley bottom to $2804 \mathrm{~m}$ at the mountain peaks. The region is characterized by a rapid ecological transition from prairie to alpine. This compressed environmental gradient and the influence of warm Chinook winds result in a rich diversity of flora and fauna. A full complement of large carnivores and ungulates can be found in this region, including grizzly bear (Ursus arctos), black bear (Ursus americanus), bobcat (Lynx rufus), lynx (Lynx canadensis), cougar (Puma concolor), coyote (Canis latrans), wolf (Canis lupus), wolverine (Gulo gulo), elk (Cervus elaphus), mountain goat (Oreamnos americanus), moose (Alces alces), mule deer (Odocoileus hemionus), white-tailed deer (Odocoileus virginianus), and Rocky Mountain bighorn sheep (Ovis canadensis).

Highway 3, which runs $44 \mathrm{~km}$ through the length of the municipality, is a major transportation route, supporting over 6000 vehicles/day (Alberta Transportation and Infrastructure 2005a). Wildlife mortality caused by collisions with vehicles on Highway 3 (approximately 109 large mammal deaths reported annually) is recognized as both a major human safety concern and a wildlife conservation issue. The region is a high priority for conservation planning because it is a key linkage zone within the Rocky Mountains for regional-scale wildlife movement (Carroll et al. 2001, Weaver 2001). Researchers have identified Highway 3 as having the potential to act as a barrier to wildlife movement patterns for large carnivores and ungulates (Weaver 2001, Apps et al. 2004).

To address the increasing volume of traffic along Highway 3, the Province of Alberta has proposed an expansion and realignment of the highway through the Municipality of Crowsnest Pass (Alberta Transportation and Infrastructure 2005b). The expansion of Highway 3, from two to four lanes in the next 10-15 years, has the potential to increase the direct mortality of wildlife and exacerbate the existing regional barrier effect of the highway. It is therefore essential that decision makers acquire 
adequate information on wildlife use patterns and existing mortality zones to best avoid and mitigate the effects of an expanded highway. Currently, information pertaining to wildlife movement in the Crowsnest Pass is largely limited to mortality data collected by local government agencies and highway maintenance contractors.

\section{Road Watch in the Pass}

The Miistakis Institute (Miistakis; www.rockies.ca ), an applied research institute affiliated with the University of Calgary, was invited to participate in several research and planning exercises in Crowsnest Pass. This involvement resulted in the identification of a dearth of recorded information concerning wildlife crossing areas along Highway 3. However, it was recognized that the local residents possessed a significant interest and level of knowledge concerning regional wildlife. In the face of impending highway expansion and the need for information to facilitate highway mitigation, it was determined by Miistakis and a variety of community members that a citizen-science research project would be highly beneficial. Miistakis secured core funding from a private foundation and Road Watch in the Pass was initiated in the fall of 2004.

To ensure that Road Watch integrated community needs and interests, Miistakis hired a local project coordinator to guide the development and implementation of the program and act as a liaison between Miistakis and the community. The project coordinator developed a communication strategy and worked with an informal local advisory committee to determine how best to collect the wildlife crossing information. The local advisory committee included local citizens, area biologists, and representatives from local government agencies. Three approaches for collecting local information were recommended by the advisory committee: (1) an online web-based tool, (2) a callin phone service, and (3) personal interviews with knowledgeable residents. All three of these methods are used in the project. This three-pronged approach ensures that the greatest diversity of people is reached because it addresses user needs across generations and does not restrict participation to people with access to a computer. Here, we focus on the primary mechanism of participation in Road Watch, the user-friendly web-based tool.
Participants in Road Watch are recruited through posters, community media announcements, local demonstrations of the web-based tool, and personal communication. The project website is an innovative and effective mechanism to solicit citizen participation. The project website describes the purpose and importance of the project and provides access to an online GIS mapping tool (Fig. 1). Here, participants can enter wildlife observations, access tutorials for using the interactive mapping tool and wildlife identification, and view cumulative results from the project. The online mapping tool includes an interactive map of Crowsnest Pass, with spatial layers representing roads, railways, lakes, rivers, towns, and the demarcation of local landmarks (Fig. 2). A highresolution $(1 \mathrm{~m})$ digital aerial photograph mosaic is provided as a background to assist participants in accurately locating their observation on the map. Participants can zoom in and out or turn layers on and off to assist in positioning their wildlife observation. Once users have located their observation site on the interactive map, they are prompted to describe the details of their wildlife sighting (Fig. 3). The input form requests information on: species observed, age, adjacent to or crossing the road, status (dead, alive, or injured), location description (the coordinates of the wildlife observation are automatically entered from the mapping tool), date, time, and additional comments. Once the observations are entered into the database, users can view their personal contributions to the project over time and view all contributed observations (Fig. 4).

The online mapping tool facilitates the collection of local observations into a useable format. Once observations are entered on the website, the information is readily available to be displayed in maps or converted to tabular data for analysis. This allows easy access for researchers and timely feedback to participants and the community. Monthly participant updates are circulated to all participants and published in the local newspapers to increase awareness of the project and solicit new volunteers.

\section{Preliminary comparison of Road Watch wildlife crossing observations and mortality data}

One of the aims of this study was to examine the relationship between more conventional data collection methods and Road Watch citizen-science 
Fig. 1. Road Watch website home page.

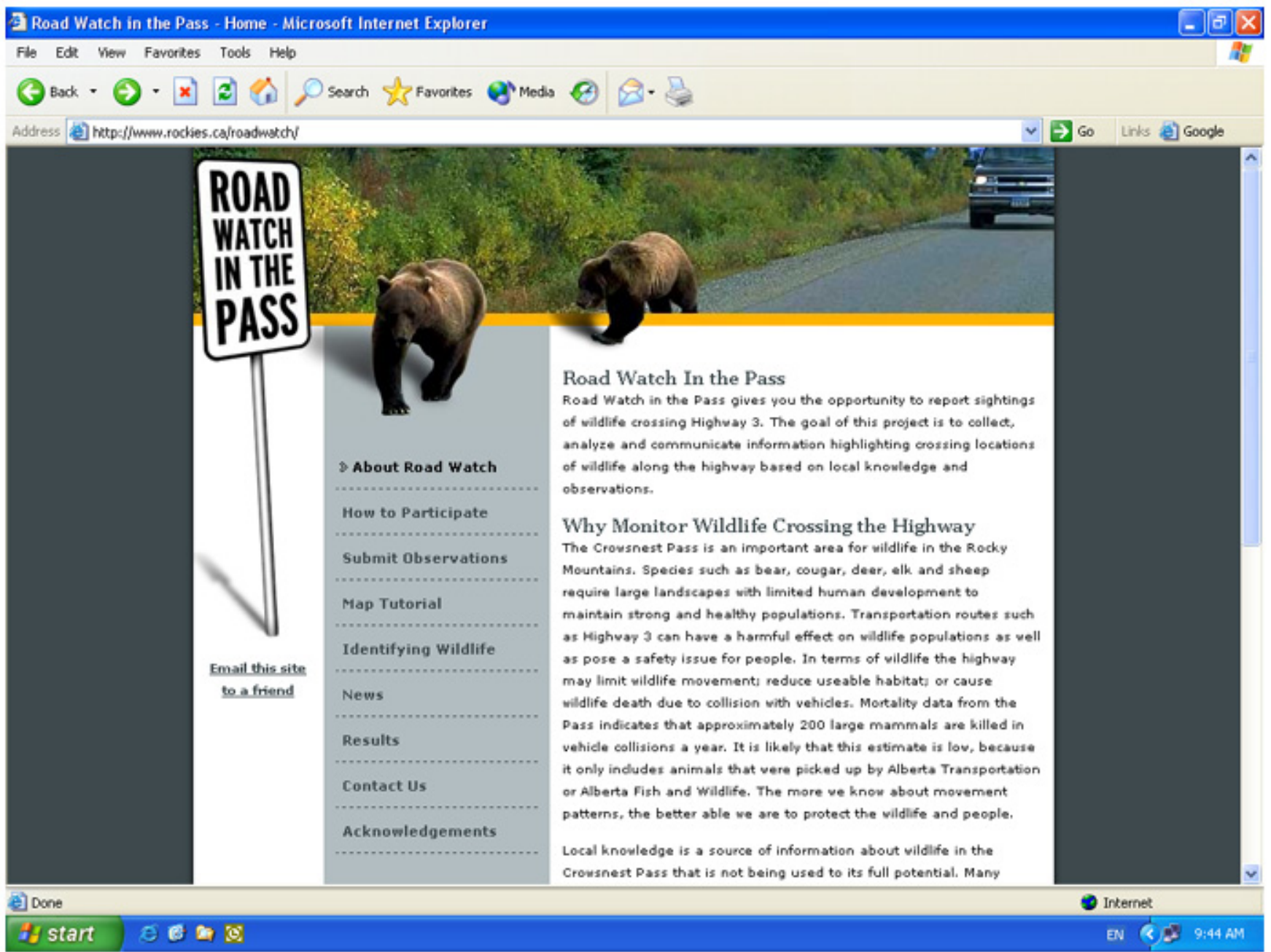

data. Here, we provide one example of how this information can be compared. Road Watch crossing observations were compared with wildlife mortality data collected in the study area as a means to offer preliminary examples of future comparative analyses. Wildlife mortality data were obtained from a local government highway contractor responsible for removing wildlife killed on Highway 3 . Highway 3 was driven twice daily by the contractor during weekdays, and information was recorded on the type of species killed, date, time of day, sex, and location of the incident. Wildlife mortality information was entered into a spreadsheet and used to generate a GIS spatial layer using ArcGIS 9.0 with support from Hawth's Analysis Tools (Beyer 2004). Wildlife mortality observations and Road Watch crossing observations from November 2004-September 2005 were used in the analysis.

Road Watch crossing observations were extracted from the Road Watch observations database. There were no duplicates found in the data set for records where crossings of a species occurred on the same day within $250 \mathrm{~m}$ of the same location. Road Watch observations include: (1) crossings, where an animal was observed crossing from one side of the road to the other; (2) adjacent observations, which 
Fig. 2. Road Watch online GIS interface.

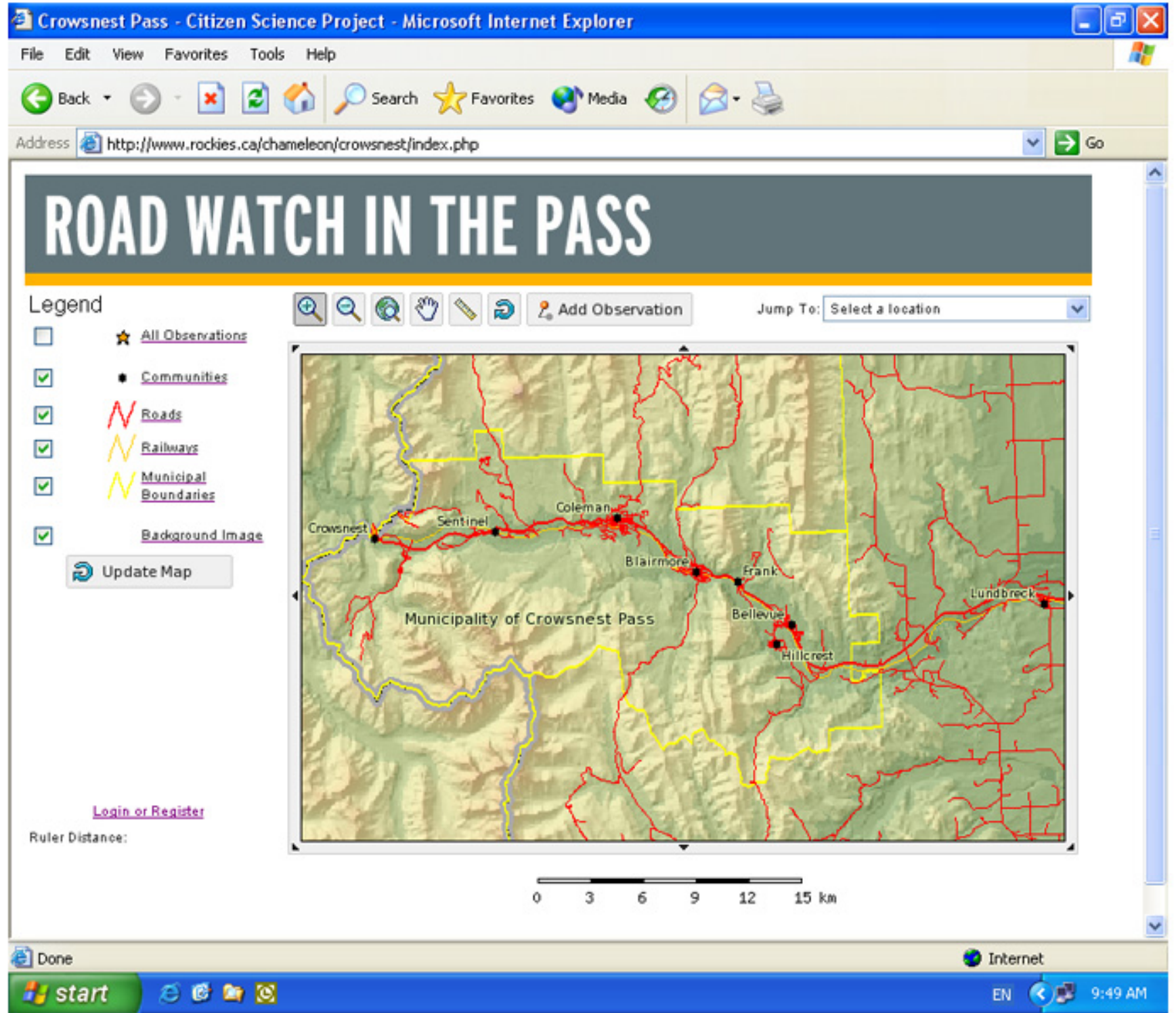

include animals adjacent to the road, but not observed crossing the road; and (3) mortality observations. Road Watch crossing observations were used to determine high-observation (crossing) zones (HOZs), i.e., clusters of animal crossing locations. The positional accuracy of Road Watch data is unknown, but we assumed that grouping the data into 250-m zones would account for errors in positional accuracy. This distance was determined by assessing the median distance between local landmarks (Beyer 2004), which were determined through consultation with area citizens. Local landmarks were used to determine locations of both Road Watch and mortality observations. The average distance between local landmarks was 500 $\mathrm{m}$; therefore, the mid-point $(250 \mathrm{~m})$ was used to represent the length of a crossing zone. Other research analyzing mortality data and high-collision 
Fig. 3. Road Watch wildlife observation form.

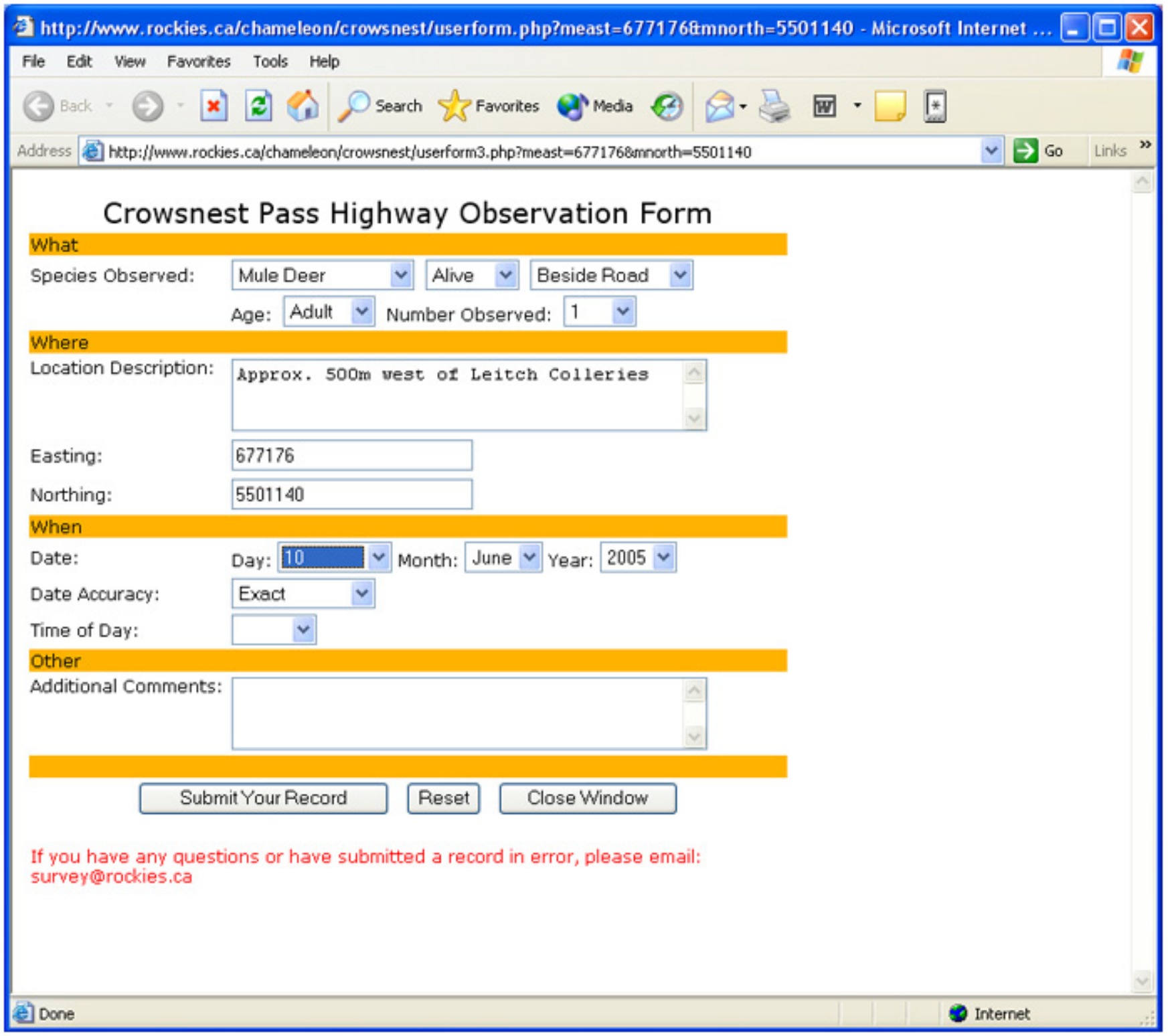

zones used zones from 100-250 m for small-scale studies to $1 \mathrm{~km}$ for regional assessments (Malo et al. 2004, Taylor and Goldingay 2004). Highway 3 was divided into $250-\mathrm{m}$ segments, with segment 0 located at the western edge of the study area and extending east for a total of 181 segments. HOZs were identified using a Poisson distribution, which assigns probabilities to the number of observations expected in a road segment given a random distribution (Boots and Getis 1988, Malo et al. 2004). The Poisson distribution assigns probabilities using $\lambda$ (mean number of observations per segment), where

$$
p(x)=\lambda^{x} /\left(x / g^{h}\right)
$$


Fig. 4. Road Watch data displayed on the mapping tool.

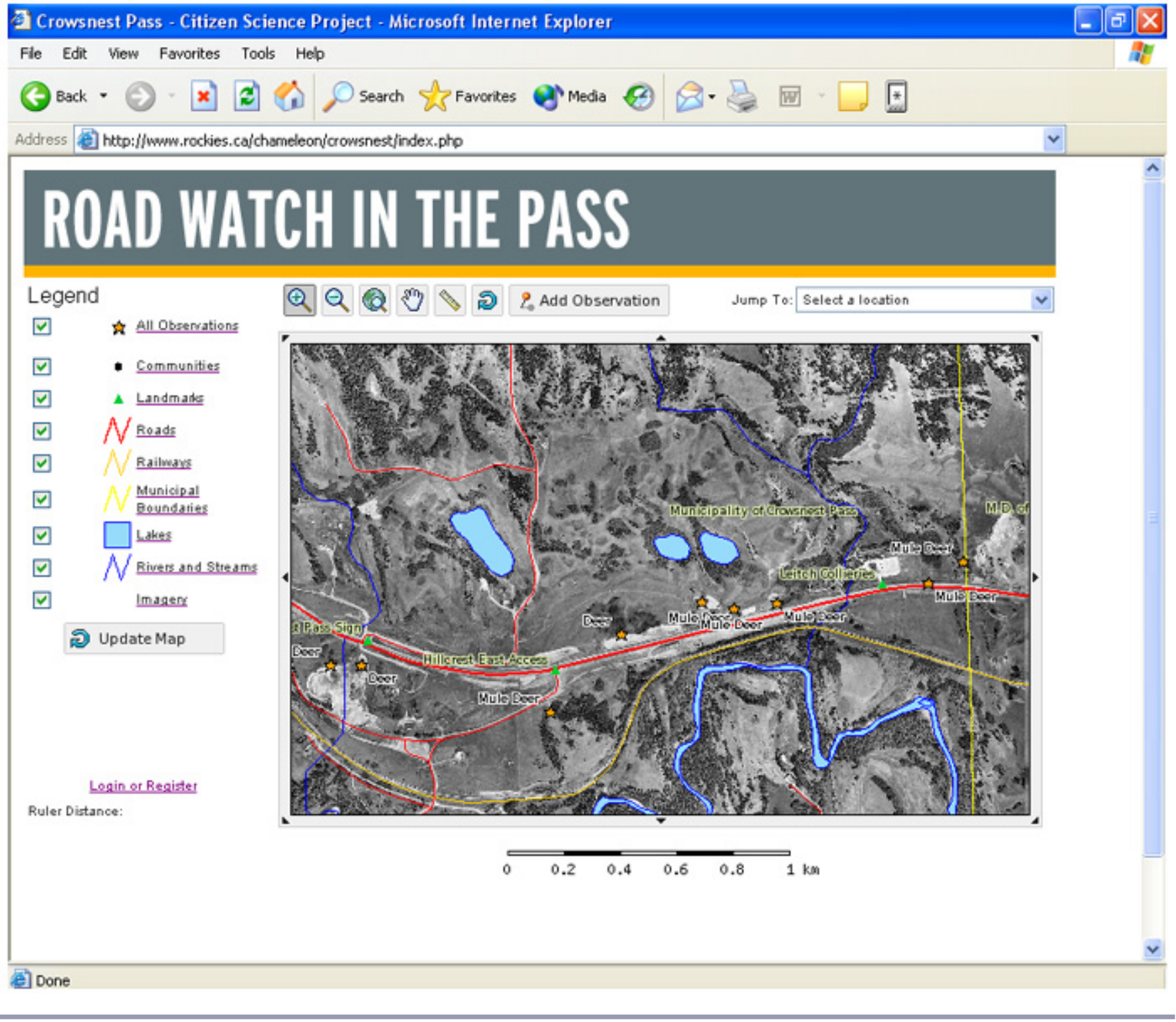

A 95\% Poisson distribution cut-off was used to identify the number of observations per segment that constituted a HOZ.

HOZs identified using Road Watch data were compared to high mortality zones (HMZs) identified using Highway 3 wildlife mortality data (same methodology as described above for Road Watch data) using the Kappa index of agreement (KIA; Congalton 1991):

$$
K=\frac{N \sum_{i-1}^{r} x_{i i}-\sum_{i-1}^{r}\left(x_{i+}^{*} x_{+i}\right)}{N^{2}-\sum_{i-1}^{r}\left(x_{i+}+x_{+i}\right)}
$$


KIA measures the similarity between two maps using indices from 0 (no spatial agreement) to 1 (perfect spatial agreement). Values $>0.75$ indicate excellent similarity, $0.45-0.75$ indicate fair to good similarity, and $<0.45$ indicate poor agreement (Campbell 1996). To determine if the KIA was statistically significant, a $Z$ score was calculated, where

$Z=k /\left(\operatorname{var}(k)^{0.5}\right)$

If the $Z$ score was greater than the identified $Z$ score at 0.05 significance, then the KIA value represents the percent agreement better than expected by chance alone (Siegel and Castellan 1988).

\section{RESULTS}

\section{Citizen science}

Road Watch was officially launched in November 2004. In the first 11 months, Road Watch engaged 58 participants who contributed 713 wildlife crossing observations through the online mapping tool (56 participants) and call-in service (2 participants), including: 286 mule deer, 118 bighorn sheep, 88 white-tailed deer, 88 unidentified deer species, 36 elk, 32 moose, 3 mountain goat, 12 coyote, 12 black bear, 6 cougar, 4 grizzly bear, 3 wolf, and 25 other wildlife observations, including birds and mesopredators. With the exception of wolverine, bobcat, and lynx, the Road Watch observations represented the full compliment of large mammals that are present in Crowsnest Pass. The total observations represented 94 crossing observations and 622 observations adjacent to Highway 3. All 94 crossing observations were recorded as alive. Of the 622 observations adjacent to Highway 3, 34 were recorded as dead.

To determine the degree to which Road Watch has engaged citizens in participating in the project, we looked at the total number of observations entered, as well as the number of volunteers that used the tool more than once. Since its inception, an average of five new volunteers has joined Road Watch each month. The median contribution per participant was four observations, with $70 \%$ of the participants submitting observations on more than one occasion.
The number of individual observations ranged from 1 to 209 .

\section{Preliminary comparison of Road Watch wildlife crossing observations and mortality data}

A total of 94 crossing observations from Road Watch and 105 wildlife mortality observations from highway maintenance contractors were included in the analysis for the same 11-month period (November 2004-September 2005), and the species composition of these data sets was compared (Table $1)$.

The mean number of Road Watch crossing observations per $250-\mathrm{m}$ segment was 0.564 . At a 95\% cut-off, any segment with two or more crossings was considered a high-observation crossing zone (HOZ). There were $21 \mathrm{HOZs}$, ranging in length from $250 \mathrm{~m}$ to $1250 \mathrm{~m}$ (where adjacent HOZs occurred) and equating to $5.3 \mathrm{~km}$ of the $44-$ $\mathrm{km}$ stretch of road. The mean number of wildlife mortality observations per $250-\mathrm{m}$ segment was 0.575 . This equated to the same cut-off value and number of high-mortality zones (HMZs) as the Road Watch crossing observations, but with a range from $250 \mathrm{~m}$ to $500 \mathrm{~m}$ in length. The location of HOZs and HMZs were compared spatially (Fig. 5). The KIA was $14 \%$, with a significant $Z$ score of $Z$ $=1.858(P=0.05$ at $Z=1.65)$.

\section{DISCUSSION}

\section{Citizen science}

The results indicate that 56 local citizens (approximately $1 \%$ of the local population) are using the web-based tool to enter wildlife observations. The number of wildlife observations, including both those crossing and adjacent to the road, is significant considering that, on an annual basis, an average of 109 large mammals are recorded, and the mortality data is one of the primary data sources used in discussions of mitigation.

During the development phase, a local advisory group composed of seven individuals provided direct feedback on the development of the webbased mapping tool. Direct feedback on participant updates, the web-based mapping tool, and projectrelated news are regularly emailed to the project 
Table 1. Species compositions of Road Watch (RW) and wildlife mortality (WM) data.

\begin{tabular}{|c|c|c|}
\hline Species & RW (\%) & $\mathrm{WM}(\%)$ \\
\hline Mule deer & $47(50)$ & $55(58)$ \\
\hline White-tailed deer & $14(15)$ & $32(34)$ \\
\hline Deer & $11(12)$ & $0(0)$ \\
\hline Bighorn sheep & $5(5)$ & $5(5)$ \\
\hline Elk & $0(0)$ & $3(3)$ \\
\hline Moose & $4(4)$ & $4(4)$ \\
\hline Grizzly bear & $2(2)$ & $0(0)$ \\
\hline Black bear & $2(2)$ & $0(0)$ \\
\hline Cougar & $1(1)$ & $0(0)$ \\
\hline Coyote & $5(5)$ & $0(0)$ \\
\hline Other & $3(3)$ & $1(1)$ \\
\hline
\end{tabular}

coordinator or communicated at local demonstrations of the tool. To date, 12 individuals $(20 \%$ of participants) have provided recommendations or suggestions for improving the tool or for presentations of results in participant updates. If a participant's request cannot be accommodated, the project coordinator contacts the participant to provide an explanation. Some examples of feedback from participants that were incorporated in the mapping tool include the ability to view a spatial layer on the website that displays their total observations and a password reminder tool. Examples of participant requests for participant updates include statistics on the number of crossing and adjacent observations and the number alive and dead, as well as requests for the number of specific geographic areas or specific species displayed on the maps.

\section{Preliminary comparison of Road Watch wildlife crossing observations and mortality data}

This analysis was performed to highlight preliminary findings of where large mammals cross Highway 3 using two independent data sets. Decision makers should use this information cautiously because it represents only 1 year of data. 
Fig. 5. Comparison of Road Watch wildlife high-crossing and high-mortality zones along Highway 3.

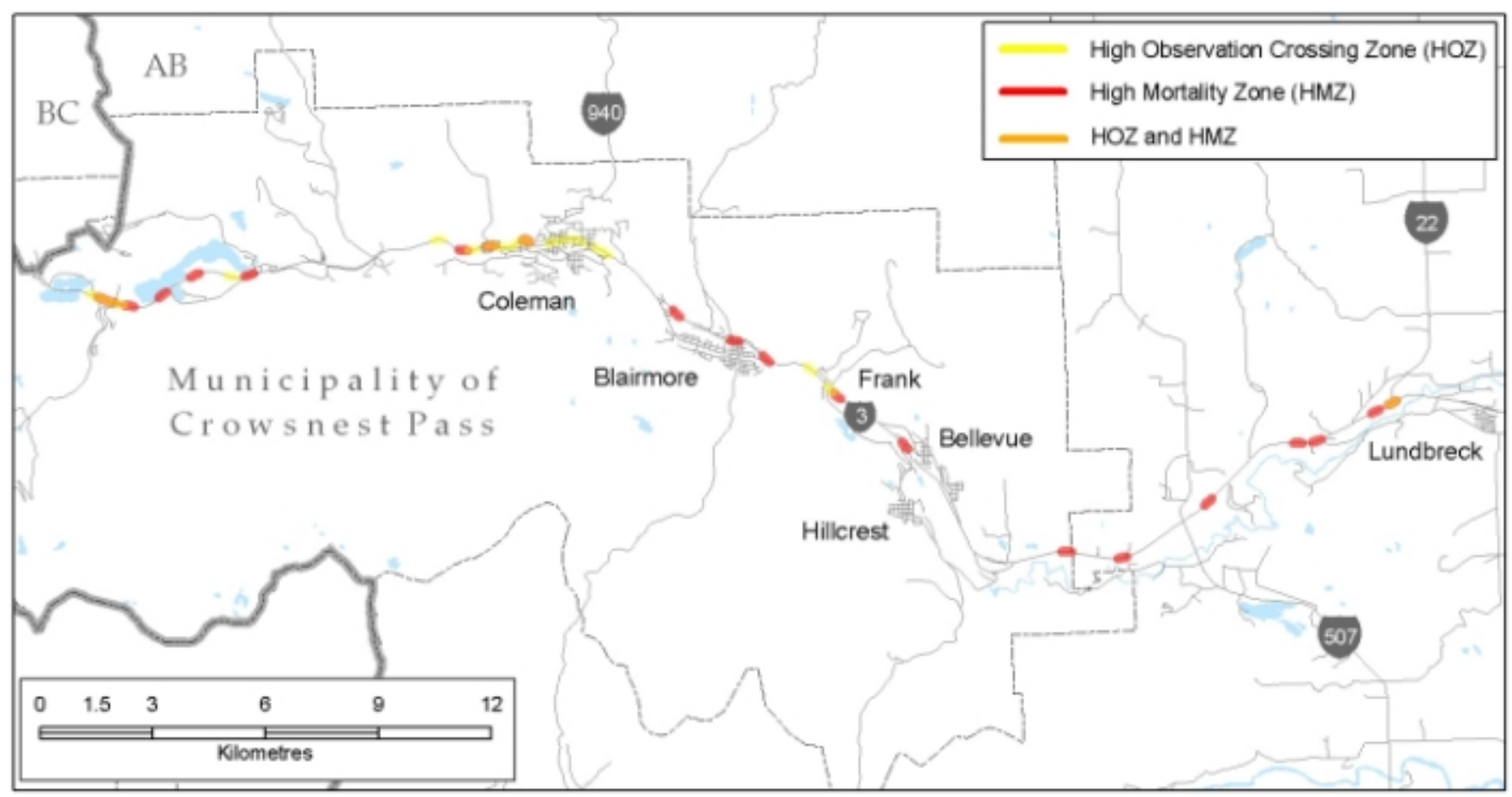

A review of 8 years of mortality data in the study area showed strong variation in HMZs between years, indicating the importance of using multiple years in analyses identifying zones of wildlife crossings. Furthermore, both data sets are subject to limitations in observational spatial accuracy. Road Watch data were not collected systematically, likely resulting in an unequal representation of observations along Highway 3.

The two data sets had a similar number of records. These data sets indicate both successful and unsuccessful crossings. Additionally, the species composition was similar between the data sets, with the highest numbers for deer (mule deer and whitetailed deer) and bighorn sheep.

The preliminary results demonstrate that integrating data collection methods, including the use of citizen science, has the potential to increase the amount of information and provide unique insights regarding previously unknown phenomena. For example, Road Watch crossing observations were compared to mortality data to determine if HMZs accurately represent crossing locations (Fig. 5). Although each data set identified 21 zones with more than the expected number of crossing or mortality observations, there was spatial variation in their locations. This is exemplified by a visual display of HOZs and HMZs that highlights the spatial variation between the data sets (Fig. 5). The comparison of the data sets indicates that, out of the $5.25 \mathrm{~km}$ of HOZs and HMZs, $1.5 \mathrm{~km}(29 \%)$ of the zones occurred in the same location. This low level of agreement may be influenced by the unequal sampling of Road Watch data; it is possible that certain sections of Highway 3 are driven more regularly. The difference in data sets has important ecological implications because it is often assumed that mortality zones translate to wildlife crossing zones. However, mortality zones may be related to specific road characteristics, such as curvature or topography, and wildlife may cross in other areas that offer more desirable characteristics, such as improved line of sight or preferred habitat.

The KIA (14\%) indicates that there is a high degree of difference between the data sets. This type of 
information is important when considering highway mitigation and design options. By recognizing the spatial disparity between mortality zones and observation zones, one can begin to examine the attributes associated with each in an attempt to improve wildlife crossing opportunities. For example, further research may identify attributes associated with mortality zones that are absent from crossing locations, which can help inform highway alignment and mitigation efforts. By limiting access to single information sources, the identification of crossing locations is compromised. This issue is of considerable importance in Crowsnest Pass, where pending highway expansion has the potential to further restrict wildlife movements.

\section{Evolution into community-based research}

This project has successfully engaged local citizens in using the Road Watch web-based mapping tool to enter wildlife crossing information. However, we did not address the project's ability to engage citizens in other wildlife movement and highway mortality issues in Crowsnest Pass. Furthermore, it is too early to assess the success of the project in creating social change. A mechanism that has been successful at fostering social change is communitybased research (CBR). CBR is "conducted by, for [,] or with the participation of community members" (Chopyak 2001, page 377). Examples emerging from the nascent literature on CBR report success in fostering a learning environment that leads to direct action and behavioral change in participating communities (Trumbell et al. 2000, Robertson and McGee 2003, Savan et al. 2003, Evans et al. 2005). Road Watch was developed with an ultimate goal of linking researchers and citizens in a learning process that strengthens the information base and the number of individuals informed about wildlife movement across Highway 3. For Road Watch to evolve from a citizen-science project to a CBR project, citizen involvement would need to increase and diversify. Numerous efforts are being made to ensure that participants are involved in decisions about the project, such as direct requests for feedback, planned meetings between researchers and participants, and the potential development of a formal advisory group. It is our intention that the role of citizen participation will increase as the project moves into its next phase, and that participants will take a more active role in project development and promotion, analysis and presentation of the results, and data dissemination to the local community. Road Watch goals related to fostering an environment to create social change will be evaluated once these initiatives have been firmly established.

Responses to this article can be read online at: http://www.ecologyandsociety.org/vol11/iss 1/art11/responses/

\section{Acknowledgments:}

We thank the community of Crowsnest Pass and the participants of Road Watch. Thanks to Janet Quinn, the local project coordinator, for her continued efforts in the Pass, and Ken Sanderson for developing the online tool and providing technical support. Thanks also to our financial sponsors: The Woodcock Foundation, Alberta Ecotrust Foundation, TD Friends of the Environment Foundation, Shell Environmental Fund, and the University of Calgary.

\section{LITERATURE CITED}

Alberta Transportation and Infrastructure. 2005a. Alberta highways 1 to 983 traffic volume history. [online] URL: http://www.trans.gov.ab.ca/ Content/doctype182/production/hwy3funcplan.htm

Alberta Transportation and Infrastructure. 2005b. Highway 3 planning and functional study. [online] URL: http://www.trans.gov.ab.ca/Content/ doctype181/production/hnp003.htm.

Andrews, A. 1990. Fragmentation of habitat by roads and utility corridors: a review. Australian Zoologist 26:130-141.

Apps, C. D., B. N. McLellan, J. G. Woods, and M. F. Proctor. 2004. Estimating grizzly bear distribution and abundance relative to habitat and human influence. Journal of Wildlife Management 68: $138-152$.

Au, J., P. Bagchi, B. Chen, R. Martinez, S. A. Dudley, and G. J. Sorger. 2000. Methodology for public monitoring of total coliforms, Escherichia coli and toxicity in waterways by Canadian high school students. Journal of Environmental Management 58:213-230. 
Beier, P., and S. Loe. 1992. A checklist for evaluating impacts to wildlife movement corridors. Wildlife Society Bulletin 20:434-440.

Beyer, H. L. 2004. Hawth's analysis tools for ArcGIS. Version 3.08. [online] URL: http://www.s patialecology.com/htools.

Boots, B. N., and A. Getis. 1988. Point Pattern Analysis. Sage, Newbury Park, California, USA.

Campbell, J. B. 1996. Introduction to Remote Sensing. Second edition. Guilford, New York, New York, USA.

Carroll, C., R. F. Noss, and P. C. Paquet. 2001. Carnivores as focal species for conservation planning in the Rocky Mountain region. Ecological Applications 11:961-980.

Chopyak, J. 2001. Citizen participation and democracy: examples in science and technology. National Civic Review 90(4):375-383.

Clevenger, A. P., and N. Waltho. 2000. Factors influencing the effectiveness of wildlife underpasses in Banff National Park, Alberta, Canada. Conservation Biology 14:47-56.

Congalton, R. G. 1991. A review of assessing the accuracy of classifications of remotely sensed data. Remote Sensing of Environment 37:35-46.

Eden, S. 1996. Public participation in environmental policy: considering scientific, counter-scientific and non-scientific contributions. Public Understanding of Science 5:184-204.

Evans, C., E. Abrams, R. Reitsma, K. Roux, L. Salmonsen, and P. Marra. 2005. The neighbourhood nestwatch program: participant outcomes of a citizen-science ecological research project. Conservation Biology 19:589-594.

Forman, R. T. T., and L. E. Alexander. 1998. Roads and their major ecological effects. Annual Review of Ecology and Systematics 29:207-231.

Forman, R. T. T., D. Sperling, J. A. Bissonette, A. P. Clevenger, C. D. Cutshall, V. H. Dale, L. Fahrig, R. France, C. R. Goldman, K. Heanue, J. A. Jones, F. J. Swanson, T. Turrentine, and T. C. Winter. 2003. Road ecology: science and solutions.
Island Press, Washington, D.C., USA.

Foster, M. L., and S. R. Humphrey. 1995. Use of highway underpasses by Florida panthers and other wildlife. Wildlife Society Bulletin 23:95-100.

Heiman, M. K. 1997. Science by the people: grassroots environmental monitoring and the debate over scientific expertise. Journal of Planning Education and Research 16:291-299.

L-P Tardif and Associates. 2003. Collisions involving motor vehicles and large animals in Canada. Prepared for Transport Canada Road Safety Directorate, Ottawa, Ontario, Canada. [online] URL: http://www.wildlifeaccidents.ca/reports. htm.

Malo, J. E., F. Suárez, and A. Díez. 2004. Can we mitigate animal-vehicle accidents using predictive models? Journal of Applied Ecology 41:701-710.

Pattengill-Semmens, C. V., and B. X. Semmens. 2003. Conservation and management applications of the reef volunteer fish monitoring program. Environmental Monitoring and Assessment 81:43-50.

Robertson, H. A., and T. K. McGee. 2003. Applying local knowledge: the contribution of oral history to wetland rehabilitation at Kanyapella Basin, Australia. Journal of Environmental Management 69:275-287.

Savan, B., A. J. Morgan, and C. Gore. 2003. Volunteer environmental monitoring and the role of the universities: the case of citizens' environment watch. Environmental Management 31:561-568.

Seiler, A. 2005. Predicting locations of moosevehicle collisions in Sweden. Journal of Applied Ecology 42:371-382.

Sherwood, B., D. Cutler, and J. Burton, editors. 2002. Wildlife and roads: the ecological impact. Imperial College Press, London, UK.

Siegel, S., and N. J. Castellan. 1988. Nonparametric statistics for the behavioural sciences. Second edition. McGraw-Hill, New York, New York, USA.

Spellerberg, I. F. 1998. Ecological effects of roads and traffic: a literature review. Global Ecology and Biogeography 7:317-333. 
Taylor, B. D., and R. L. Goldingay. 2004. Wildlife road-kills on three major roads in north-eastern New South Wales. Wildlife Research 31:83-91.

Trombulak, S. C., and C.A. Frissell. 2000. Review of ecological effects of roads on terrestrial and aquatic communities. Conservation Biology 14:18-30.

Trumbull, D. J., R. Bonney, D. Bascom, and A. Cabral. 2000. Thinking scientifically during participation in a citizen-science project. Science Education 84:265-275.

Weaver, J. L. 2001. The transboundary Flathead: a critical landscape for carnivores in the Rocky Mountains. Wildlife Conservation Society Working Paper Number 18. Bronx, New York, USA. 